\title{
Comparative analysis of structural properties of Portunid Crab Hemocyanin
}

\author{
F. Giomi ${ }^{\text {a }}$, S. Raicevich ${ }^{\text {b }}$ P. Di Muro ${ }^{\text {a }}$, F. Pranovi ${ }^{\text {b }}$, M. Beltramini ${ }^{\text {a,* }}$ \\ ${ }^{a}$ Department of Biology, University of Padua, Via Ugo Bassi 58/B, 35131 Padua, Italy \\ ${ }^{\mathrm{b}}$ Department of Environmental Sciences, University of Venice, Venice, Italy
}

\begin{abstract}
In order to explore the hemocyanin adaptative potential and evolutive dynamics, we have analyzed the structural properties of this oxygencarrier protein, in some species of portunid Crabs, (Brachyura, Portunida).

We have compared the intra- and interspecific subunits patterns, in native and denaturant conditions, to estimate the phenetic relationships and the different stabilities of the protein.

(C) 2003 Elsevier Ltd. All rights reserved.
\end{abstract}

Keywords: Hemocyanin; Electrophoretic Patterns; Brachiuran Crabs; Intra-/Interspecific Comparisons

\section{Introduction}

Studies on the origin, evolution and differentiation of hemocyanin $(\mathrm{Hc})$ have mostly been performed to explain the relationships between higher taxa. Many hypotheses have been proposed for the phylogeny of crustacean and chelicerates Hcs and for closely related protein subfamilies, such as prophenoloxidase and arylphorine (Hughes, 1999; Decker and Terwilliger, 2000). The plastic responses to environmental selective pressures could have played a central role for the evolution of hemocyanin subunit heterogeneity. In order to explore this adaptive potential and try to trace the evolutive dynamics, we have analyzed the intra- and inter-specific subunit patterns in some species of Portunid Crabs, (Brachyura, Portunida). This Brachiuran family is well suited for our comparative analysis for its geographical distribution, the easiness of sampling and the considerable amount of molecular and physiological data in literature.

\section{Results}

We have analyzed, with electrophoretic and chromatographic techniques, the Hcs isolated from

\footnotetext{
* Corresponding author. Tel.: +39-49-827-6337; fax: + 39-49-8276344.

E-mail address: beltmar@civ.bio.unipd.it (M. Beltramini).
}

several populations of different species, collected in the North Atlantic ocean and in the Adriatic sea. We have carried out screening under native and denaturing conditions, and the densitometric profiles of dissociation products have been compared. As already known, the expression of different subunits of portunid crab Hcs undergo an in vivo modulation as a function of ecological parameters (Mangum, 1994). In this context we have considered seven populations of Liocarcinus depurator, each one composed from 50 to 60 crabs, sampled in different environments. We have performed PAGE, at both physiological and dissociating $\mathrm{pH}$, to determine the native association state and to explore the stability of quaternary structure. In previous chromatographic analyses we found, for modest increases of alkalinity, a very low resistance to dissociation (manuscript in preparation), yet in two populations a hexameric fraction is evident that still remains undissociated at $\mathrm{pH}$ 9.6. This is now confirmed from alkaline PAGE showing the persistance of the hexameric $\mathrm{Hc}$ fraction in one case (Fig. 1, lane D), while in other cases only the subunit pattern is evident (Fig. 1, lane C). Analysis by SDSPAGE shows three subunits for all $L$. depurator $\mathrm{Hc}$ samples. However, their relative expression within the native oligomer changes in the different populations. In detail, as a general rule, subunit 1 shows a low level of expression (a typical case is given in Fig. 1, lane A). In contrast, in other populations, this subunit is more 


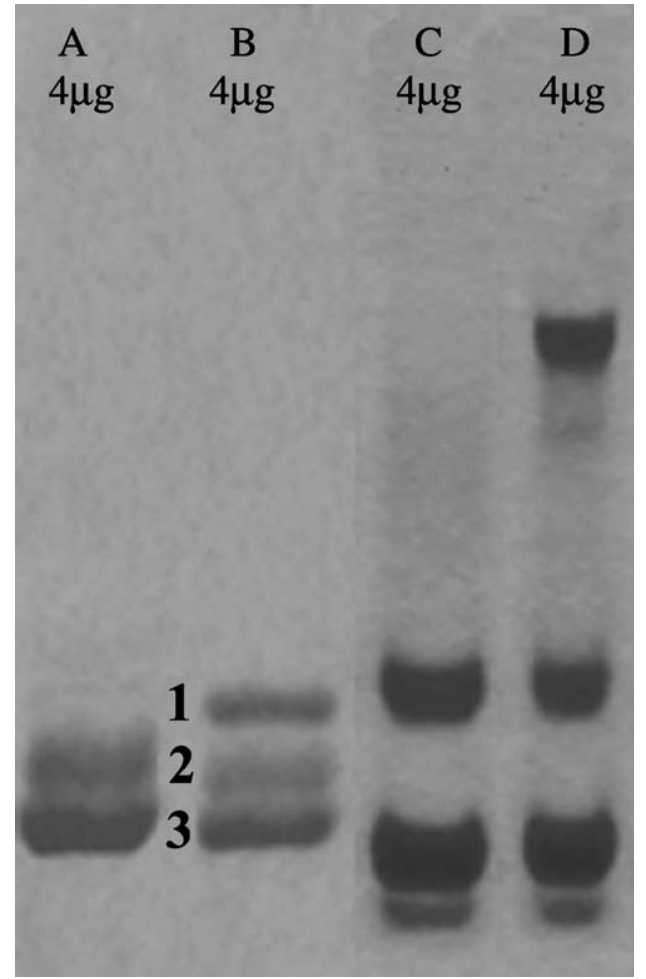

Fig. 1. Lane A: L. depurator SDS-PAGE 8.5\%. Lane B: L. depurator SDS-PAGE 8.5\%. Lane C: L. depurator Native PAGE pH 9.6, 8.5\%. Lane D: L. depurator Native PAGE pH 9.6, 8.5\%.

abundant as typically shown in Fig. 1, lane B. It is worth noting that the two cases with higher levels of expression of subunit 1 are those with highest stability of the hexameric oligomer. Thus, it is possible to correlate the stability of the oligomer with the expression of a given fraction. We have carried out the same analysis for the three different species of Portunids, verifing a similar subunit heterogeneity in structural stability and different levels of subunit expression (Fig. 2). The results of this analysis supports the hypothesis that subunit composition is almost specie-specific, but also that closely related species like L. holsatus and L. marmoreus share a common subunit pattern. The phenotypic differences appear to be in accordance with the phylogenetic analysis based on molecular and morphological data proposed by several authors (Mantovani et al., 1992; Trentini et al., 1987; Trentini et al., 1992).

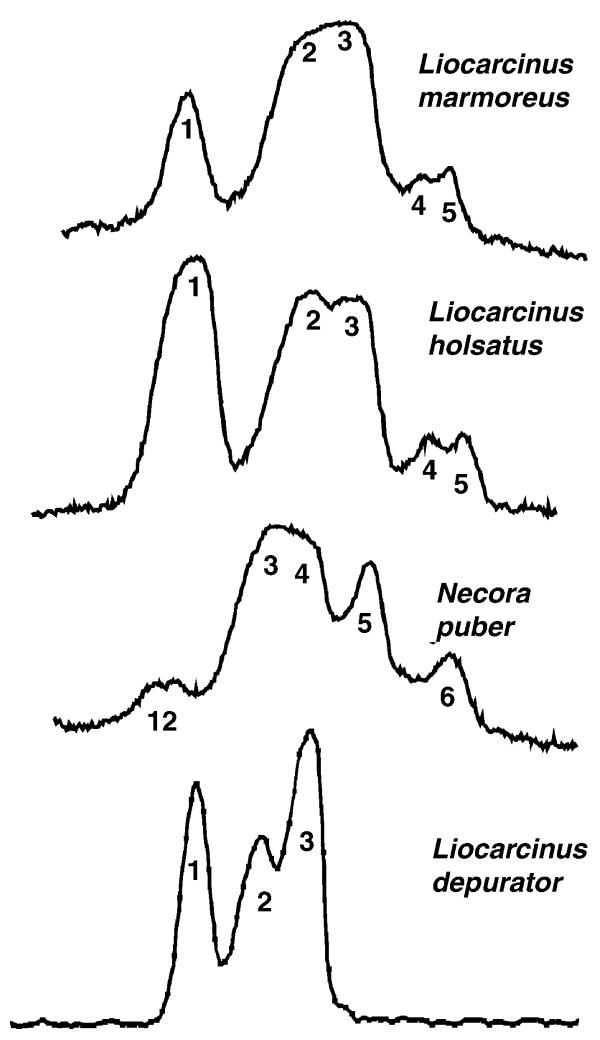

Fig. 2. Densitometric profiles of Portunid hemocyanins in SDS-PAGE at $8.5 \%$.

\section{References}

Decker, H., Terwilliger, N., 2000. Cops and robbers: putative evolution of copper oxygen-binding proteins. J. Exp. Biol. 203, 1777-1782.

Hughes, A.L., 1999. Evolution of the arthropod prophenoloxidase/ hexamerin protein family. Immunogenetics 49, 106-114.

Mangum, C.P., 1994. Subunit composition of hemocyanin of Callinectes sapidus: phenotypes from naturally hypoxic waters and isolated oligomers. Comp. Biochem. Physiol. 108B, 537-541.

Mantovani, M., Scali, V., Froglia, C., 1992. Allozymic characterization and phyletic relationships among four species of the genus Liocarcinus STIPSON 1871 (Crustacea Decapoda). Zool. Anz. 229 (5/6), 237-247.

Trentini, M., Corni, M.G., Froglia, C., 1916. The chromosomes of Liocarcinus vernalis (Risso, 1916) and Liocarcinus depurator (L., 1758) (Decapoda, Brachiura, Portunidae). Biol. Zent. B1. 108, 163-166.

Trentini, M., Corni, M.G., Froglia, C., 1884. The chromosomes of Carcinus mediterraneus Czerniavsky, 1884, Liocarcinus maculatus (Risso, 1827) and Necora puber (L., 1767) (Decapoda, Brachyura, Portunidae). Zool. Anz. 228 (1/2), 39-44. 